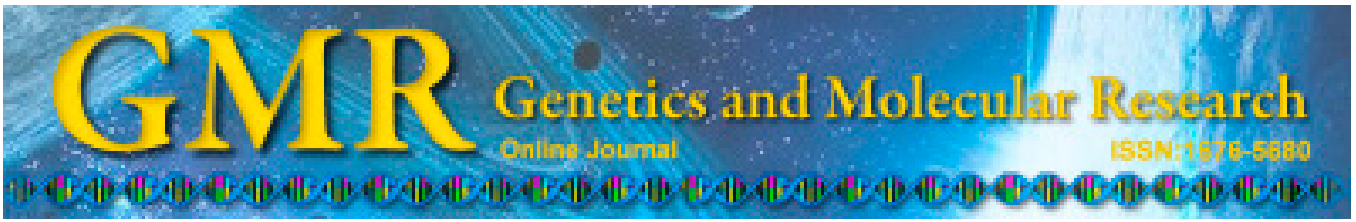

\title{
Assessing hygienic behavior of Apis mellifera unicolor (Hymenoptera: Apidae), the endemic honey bee from Madagascar
}

\author{
H. Rasolofoarivao ${ }^{1,2,3}$, H. Delatte ${ }^{2}$, L.H. Raveloson Ravaomanarivo ${ }^{1}$, \\ B. Reynaud ${ }^{2}$ and J. Clémencet ${ }^{3}$ \\ ${ }^{1}$ Département d'Entomologie, Faculté des Sciences, \\ Université d'Antananarivo, Antananarivo, Madagascar \\ ${ }^{2}$ UMR PVBMT, CIRAD, Saint-Pierre, La Réunion, France \\ ${ }^{3}$ UMR PVBMT, Université de La Réunion, Saint Denis, \\ La Réunion, France \\ Corresponding author: J. Clémencet \\ E-mail: johanna.clemencet@univ-reunion.fr
}

Genet. Mol. Res. 14 (2): 5879-5889 (2015)

Received July 7, 2014

Accepted December 12, 2014

Published June 1, 2015

DOI http://dx.doi.org/10.4238/2015.June.1.5

\begin{abstract}
Hygienic behavior (HB) is one of the natural mechanisms of honey bee for limiting the spread of brood diseases and Varroa destructor parasitic mite. Objective of our study was to measure HB of Apis mellifera unicolor colonies $(\mathrm{N}=403)$ from three geographic regions (one infested and two free of $V$. destructor) in Madagascar. The pin-killing method was used for evaluation of the HB. Responses were measured from $3 \mathrm{~h} 30 \mathrm{~min}$ to $7 \mathrm{~h}$ after perforation of the cells. Colonies were very effective in detecting perforated cells. In the first $4 \mathrm{~h}$, on average, they detected at least $50 \%$ of the pin-killed brood. Six hours after cell perforation, colonies tested $(\mathrm{N}=91)$ showed a wide range of uncapped ( 0 to $100 \%$ ) and cleaned cells (0 to $82 \%$ ). Global distribution of the rate of cleaned cells at $6 \mathrm{~h}$ was multimodal and hygienic responses could be split in three classes. Colonies from the three regions showed a significant difference in HB responses. Three hypotheses (geographic,
\end{abstract}


genetic traits, presence of $V$. destructor) are further discussed to explain variability of $\mathrm{HB}$ responses among the regions. Levels of $\mathrm{HB}$ efficiency of A. mellifera unicolor colonies are among the greatest levels reported for A. mellifera subspecies. Presence of highly hygienic colonies is a great opportunity for future breeding program in selection for HB.

Key words: Hygienic behavior; Pin-test; Apis mellifera unicolor; Varroa destructor

\section{INTRODUCTION}

Apis mellifera unicolor, the endemic honey bee of Madagascar (Latreille, 1804) has a major role in both natural and agroecosystems. Indeed, in this hotspot of biodiversity (Mittermeier et al., 2011), this endemic honeybee contributes to the pollination of phanerogam plants, among which $80 \%$ are endemic (Ganzhorn et al., 2001).

Varroa destructor, a serious pest of honey bee (A. mellifera) has been reported for the first time on the island in 2010 (OIE notification, February 11, 2010) and was found in nine administrative regions in 2012 (Rasolofoarivao et al., 2013). Dramatic losses of managed colonies have been recorded in infested areas (Rasolofoarivao et al., 2013), whereas feral honey bee losses are still unknown. To limit the spread of this ectoparasite, exchange of colonies between districts has been strictly forbidden since 2010, and destruction of parasitized colonies and hives was recommended in infested apiaries. Despite these governmental measures, $V$. destructor has continued to spread in other areas (Rasolofoarivao, personal communication). Beekeepers started using other techniques to control V. destructor, such as removing male brood cells or using chemical products (Amitraz, Apivar, thyme essentials oils, personal communication). However, the use of chemicals has its limits, since residues can remain in the honey, they can have negative effects on honey bee health (Johnson et al., 2010), and $V$. destructor strain(s) could develop resistance to the pesticides, such as acaricide (Lodesani et al., 2009). Furthermore, the use of traditional hives (with non-removable frames) limits further the control, and in addition, chemical products are expensive for small scale beekeepers. Hence, long-term measures are needed to protect beekeeping.

Hygienic behavior (HB) is a natural behavioral defense mechanism against attacks by $V$. destructor (Spivak, 1996). Basically, HB of a worker is defined as the ability to detect and uncap the cells with dead or infected brood, and remove the brood from the nest (Rothenbuhler, 1964). Highly hygienic colonies are more sensitive to odor of dead brood (Masterman et al., 2001), and they remove it in a shorter time than others (Gramacho, 1999; Palacio et al., 2005). In infested colonies, the removal of damaged brood inside the sealed cell interrupts $V$. destructor growth, leads to a prolonged female phoretic phase, and decreases the number of offspring per mother mite (Fries et al., 1994); therefore, it has a major influence on the population dynamics of $V$. destructor.

Hygienic behavior in honey bee is highly variable among and within populations and subspecies (Spivak and Gilliam, 1998; Athreya and Reddy, 2013). The high tolerance to $V$. destructor of its natural host Apis cerana (Boecking and Spivak, 1999) and of the Africanized honey bee (Guerra Jr. et al., 2000) could in part be due to greater HB efficiency (see also Aumeier et al., 2000). 
Since HB has a genetic basis (Rothenbuhler, 1964) and is a heritable trait (Boecking and Spivak, 1999) much attention has been directed at breeding $V$. destructor-tolerant honey bee lines. The proportion of highly hygienic colonies has been increased through artificial selection in commercial European and American honey bee populations (Spivak and Gilliam, 1998; Palacio et al., 2000; Gregorc and Lokar, 2011).

The HB behavior in the endemic honey bee subspecies from Madagascar, A. mellifera unicolor has not been studied yet. Therefore, our objectives were i) to indirectly measure the potential tolerance of $A$. mellifera unicolor to $V$. destructor by HB tests, ii) to compare variability of HB response in colonies from different regions, and iii) to classify the colonies in different hygienic classes for future potential selection program.

\section{MATERIAL AND METHODS}

\section{Experimental site}

Hygienic tests were conducted in three geographic regions, one on the west coast (R1: Morondava), one located in the High Lands (R3: Antananarivo), and one on the east coast (R2: Ambositra) (Figure 1). Assays were performed in November 2012, from March to May 2013, and from June to August 2013 in R3, R2, and R1, respectively. Colonies from R3 were all infested by $V$. destructor, while colonies from $\mathrm{R} 1$ and $\mathrm{R} 2$ were free of mite. Colonies tested in $\mathrm{R} 3(\mathrm{~N}=28)$ belonged to a single beekeeper, while 197 and 178 tested colonies in R1 and R2, respectively, each belonged to 10 beekeepers. All hives were Dadant or Langstroth model and contained nine to 24 frames. Tests were performed on colonies containing at least four full frames of brood at all stages.

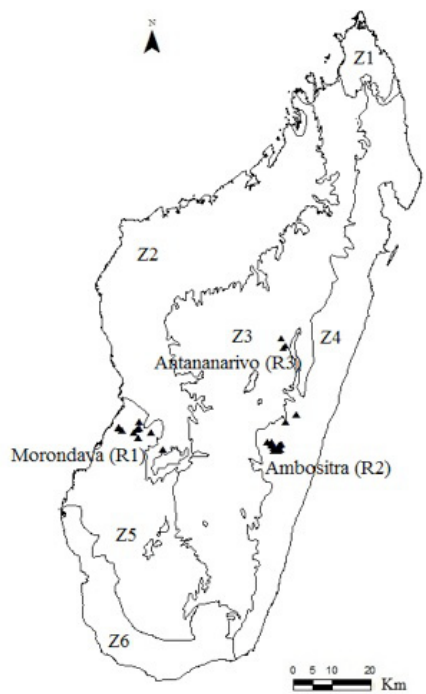

Figure 1. Distribution of the apiaries (black triangles) from three regions (R1, R2, and R3) used for pin-killing tests. Six ecological zonations (Z1, Z2, Z3, Z4, Z5, and Z6) of Madagascar are presented in the map. (Map source: Atlas de Madagascar, 2010). Z1: North: dry deciduous forest, hard tropical climate; Z2: West: dry deciduous forest, hot tropical climate during hard season; Z3: Center: high land, sub-humid forest, high-altitude tropical climate; Z4: East: wetter area of island, lowland forest, sub equatorial climate; Z5: Southwest: succulent woodlands, hard tropical climate; Z6: South: half desert, spiny thickets, hard tropical climate. 


\section{Biological materials}

We investigated mitochondrial and nuclear genetic diversity and structure of 129 colonies tested for $\mathrm{HB}$ (30 colonies from R1, 76 from R2, and 23 from R3). tRNA-leu-COII mitochondrial region (Garnery et al., 1992) was used for mitochondrial analysis. mtDNA profiles were examined by DraI restriction fragment length polymorphism in all 129 colonies. tRNA-leu-COII mtDNA amplified fragments $(\mathrm{N}=10)$ were sequenced for the control as described in Techer et al. (in press). Nuclear diversity was estimated from one individual per colony using 17 microsatellite loci (Solignac et al., 2003). DNA extraction and PCR amplifications were conducted as described in Rasolofoarivao et al. (2015). Genetic differentiation among regions was quantified by calculating pairwise $F_{\mathrm{ST}}$ values (Weir and Cockerham, 1984) implemented in Genetix 4.05 (Belkhir et al., 1996-2004). A multivariate analysis, i.e. principal components analysis (PCA) (Jombart, 2008), was used to describe the genetic structure between individuals from the three regions with adegenet package implemented in the R software version 3.01 (Development Core Team, 2013).

\section{Choice of brood killing method}

We artificially killed the brood to measure HB response as an indication of the willingness of the colony to remove mite infested brood (Boecking and Spivak, 1999; Palacio et al., 2000). The pin-killing brood method has been chosen instead of the freeze-killed method, because it is easier to use in the field, less expensive to implement, and less time and labor consuming. The tendency of honey bees to remove perforated brood is faster (Panasiuk et al., 2008) because workers can more easily recognize dead brood due to volatile compounds of the hemolymph (Gramacho et al., 1999). Since this method is handy and cheap to perform, Malagasy beekeepers could easily apply it unaided.

\section{Killing brood and hygienic categories}

HB was estimated based on the pin-killing brood method. Two square sections of comb, each containing 25 capped brood cells, i.e., 50 cells per colony, were chosen for perforation. Insect pin No. 2 was used and inserted in the middle of each cell. Pin was pushed into the body of the brood until it reached the base of the cell. Tested frame was quickly placed back in the hive after a first photograph $\left(\mathrm{T}_{0}\right)$. In $\mathrm{R} 3$, the same colonies $(\mathrm{N}=28)$ were photographed twice, at 4 and $6 \mathrm{~h}$ after the perforation. Pictures allowed us to count the number of (un)capped and (un)cleaned cells. To cover a larger time scale and avoid any potential effects of disturbance, colonies from R1 and R2 were photographed only once. Hygienic success rate of the colonies was observed from $3 \mathrm{~h} 30 \mathrm{~min}$ to $7 \mathrm{~h}$ after the pin-killing of the brood. Each colony was randomly affected to one of the eight defined time interval classes. The number of colonies tested per time class (30 min) varied from 8 to 49 .

Perforated cells were classified into four different categories (I, A, B, C): intact cells (I), partially uncapped cells (A), fully uncapped cells with brood still remaining (B), cleaned cells, i.e., fully uncapped and brood removed (C).

\section{Statistical analysis}

Three stages of response were considered. Percentages of detected cells $(A+B+C)$, 
uncapped cells $(B+C)$, and cleaned cells $(C)$ were calculated and examined at different times after pin-killing the brood. Data analysis was performed using R version 3.01 (Development Core Team, 2013). Distribution of the residuals was visually checked for normality. A generalized linear model (GLM) was used to test for the correlation between time and percentage of each cleaning stage after perforation and in each region. Distribution of the cleaned cells measured $6 \mathrm{~h}$ after perforation was examined across the whole data set $(\mathrm{N}=91)$ and for each region separately (36 colonies from R1, 27 from R2, and 28 from R3). Rebmix package (Nagode and Fajdiga, 2011) was applied to estimate the distribution mode (unimodal vs multimodal) of the global rate of cleaned cells. The Fischer test was used to test for significant differences in the distribution rates of cleaned cells between each pairwise region.

\section{RESULTS}

\section{Genetic results}

We confirmed that all tested colonies belonged to the subspecies $A$. mellifera unicolor. A single African haplotype $\left(\mathrm{A}_{\mathrm{I}}\right)$ that was previously published (Franck et al., 2001) was retrieved. DNA sequences $(\mathrm{N}=10)$ were identical to A1-Mad3 [Accession No. KF976994; Rasolofoarivao et al. (2015)]. $F_{\mathrm{ST}}$ values were 0.01 (R2/R3), 0.05 (R1/R2), and 0.11 (R1/R3), with P-values highly significant for each region pair across all loci. PCA presented in Figure 2 illustrates the nuclear genetic diversity between pre-defined colonies from the three regions.

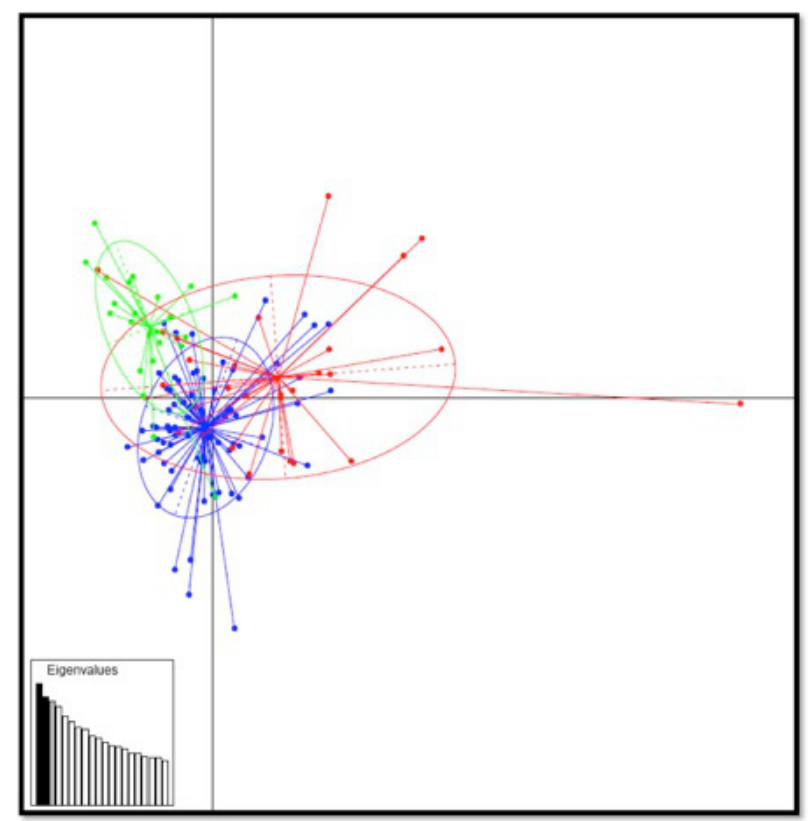

Figure 2. Principal component analysis performed on a data set of 129 individuals (30 colonies from R1, 76 from R2, and 23 from R3) genotyped at 17 microsatellite loci. Individuals are represented by dots; colors reflect geographical areas of samples (red: R1, blue: R2, and green: R3). Inertia ellipses $(66.7 \%)$ are drawn for each region. The bar graph insert displays the variance explained by the two discriminant eigen values used for plotting. 


\section{Hygienic behavior}

A total of 403 colonies from three regions were tested for HB. Variability in hygienic responses was found between colonies tested at different time intervals for each hygienic stage and each region (GLM, all $\mathrm{P}<0.05)$ (Figure 3 ). In the first $4 \mathrm{~h}$, on average, colonies had detected at least $50 \%$ of the perforated cells (Figure 3). In R3, the average percentage of detected cells reached more than $80 \%$ after $4 \mathrm{~h}$, with two colonies detecting $100 \%$ of the perforated cells. Four hours after perforation, all the colonies had already some fully uncapped cells. Nine of the tested colonies had uncapped $100 \%$ of the perforated cells within $6 \mathrm{~h}$, but none of the tested colonies had cleaned $100 \%$ of the cells within the $7 \mathrm{~h}$ of the experiment. In the same time interval, at $6 \mathrm{~h}$, colonies displayed a wide range of detected cells (32 to 100\%), uncapped cells ( 0 to $100 \%$ ) and cleaned cells (0 to $82 \%$ ) (Table 1, Figure 4).

R1



R2 $(10)(25)(30)(38)(22)(27)(08)(18)$
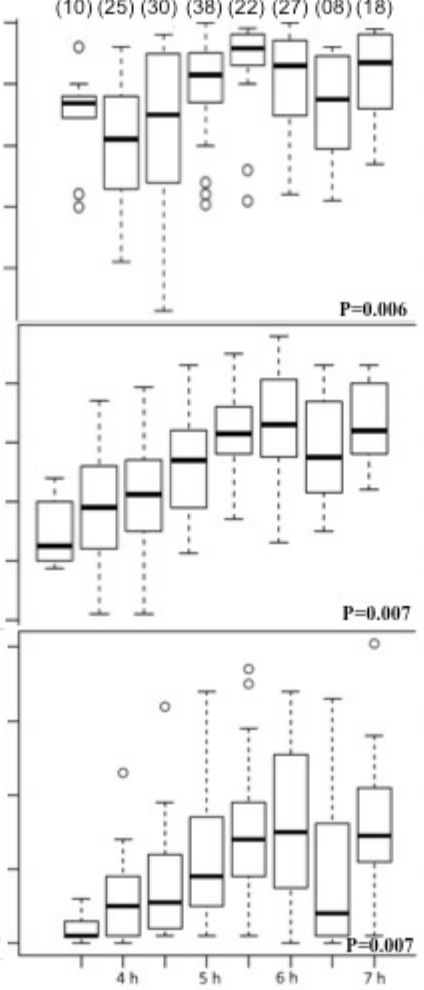

Time in hours (h)

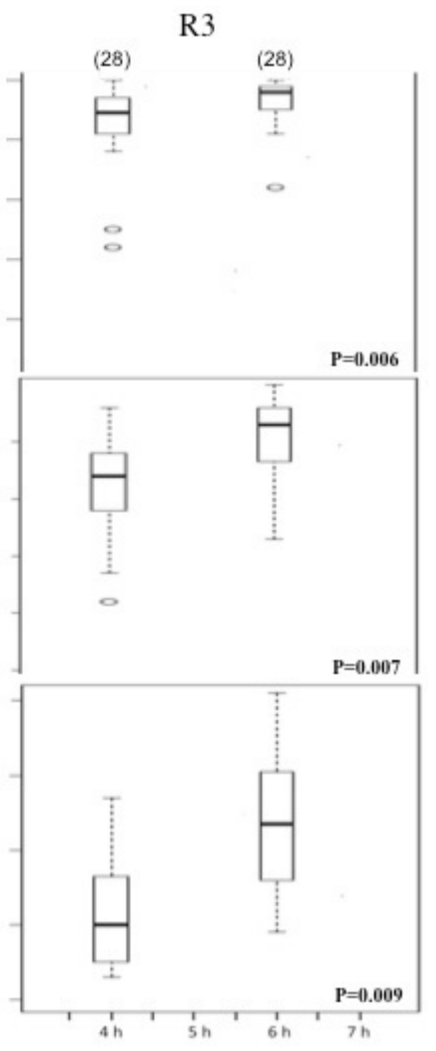

Figure 3. Hygienic responses of Apis mellifera unicolor colonies indirectly measured by the pin-killing tests at different hours after killing the brood. For each of the three regions (R1, R2, and R3) studied, percentages of detected, uncapped and cleaned cells recorded at different times after perforation and corresponding P value (GLM, $0.004<\mathrm{P}<0.011$ ) are indicated. In R1 and R2, hygienic behavior of each colony has been measured once, in R3, the same colonies have been tested twice. 
Table 1. Hygienic behavior responses $6 \mathrm{~h}$ after pin-killing the brood indicated for each region.

\begin{tabular}{|c|c|c|c|}
\hline Regions & $\%$ of detected cells & $\%$ of uncapped cells & $\%$ of cleaned cells \\
\hline \multirow[t]{2}{*}{ Morondava $(\mathrm{R} 1)(\mathrm{N}=36)$} & $32-98$ & $0-73$ & $0-65$ \\
\hline & Mean $=77 \pm 15$ & Mean $=43 \pm 20$ & Mean $=18 \pm 15$ \\
\hline \multirow[t]{2}{*}{ Ambositra (R2) $(\mathrm{N}=27)$} & $44-100$ & $26-96$ & $0-68$ \\
\hline & Mean $=82 \pm 16$ & Mean $=68 \pm 20$ & Mean $=32 \pm 21$ \\
\hline \multirow[t]{2}{*}{ Antananarivo (R3) $(\mathrm{N}=28)$} & 64-100 & $46-100$ & $18-82$ \\
\hline & Mean $=93 \pm 08$ & Mean $=82 \pm 14$ & Mean $=48 \pm 18$ \\
\hline
\end{tabular}

$\mathrm{N}=$ the number of colonies tested; numerical values for detected, uncapped, and cleaned cells are range and reported as means $\pm \mathrm{SD}$.
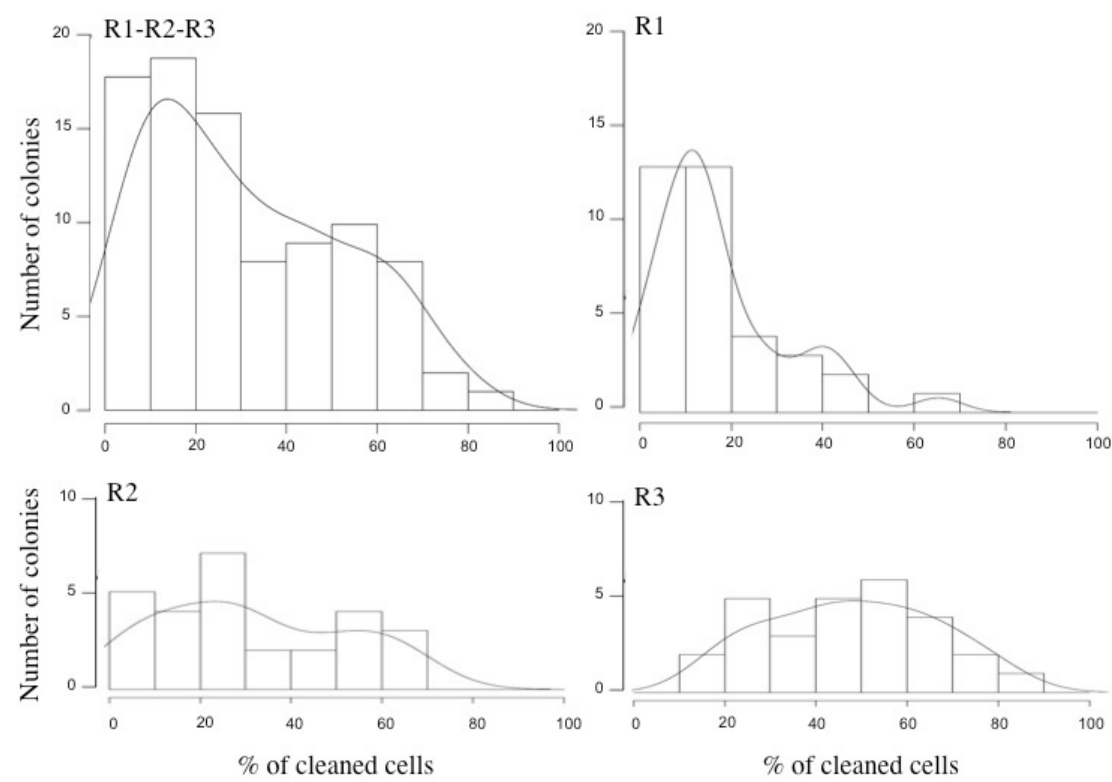

Figure 4. Distribution of the percentage of cleaned cells $6 \mathrm{~h}$ after pin-killing the brood. Density curve is presented in each graph.

\section{Distribution of the rate of cleaned cells $6 \mathrm{~h}$ after perforation}

The unimodal vs multimodal distribution tested by the Rebmix package showed that the distribution of the rate of cleaned cells was considered as multimodal, covering a range of different classes (Figure 4). Among 91 colonies examined $6 \mathrm{~h}$ after perforation, $58 \%(\mathrm{~N}=$ 53) cleaned less than $30 \%$ of the perforated cells and were designated class $1 ; 38 \%(\mathrm{~N}=35)$ cleaned between 30 to $70 \%$ of perforated cells and were designated class 2 ; and $3 \%(\mathrm{~N}=3)$ cleaned more than $70 \%$ of the perforated cells and were designated class 3 (Table 2).

Distribution of cleaned cells in colonies from $\mathrm{R} 1(\mathrm{~N}=36)$ was similar to that of the global distribution. R1 population had a great proportion of its colonies $(72 \%)$ that cleaned less than $20 \%$ of perforated cells, while in the infested region (R3), with the exception of two colonies with the rate of $18 \%$ of cleaned cells, the rate in other colonies was above $22 \%$ (Table 1, Figure 4). In R2, percentage of cleaned cells ranged from 0 to $68 \%$. Proportions of colonies belonging to each class were significantly different between each pairwise region (Fisher test, $\mathrm{P}=0.04$ for $\mathrm{R} 1 / \mathrm{R} 2,1.008 \mathrm{e}^{-5}$ for $\mathrm{R} 1 / \mathrm{R} 3$, and 0.01 for $\mathrm{R} 2 / \mathrm{R} 3$ ). 
H. Rasolofoarivao et al.

5886

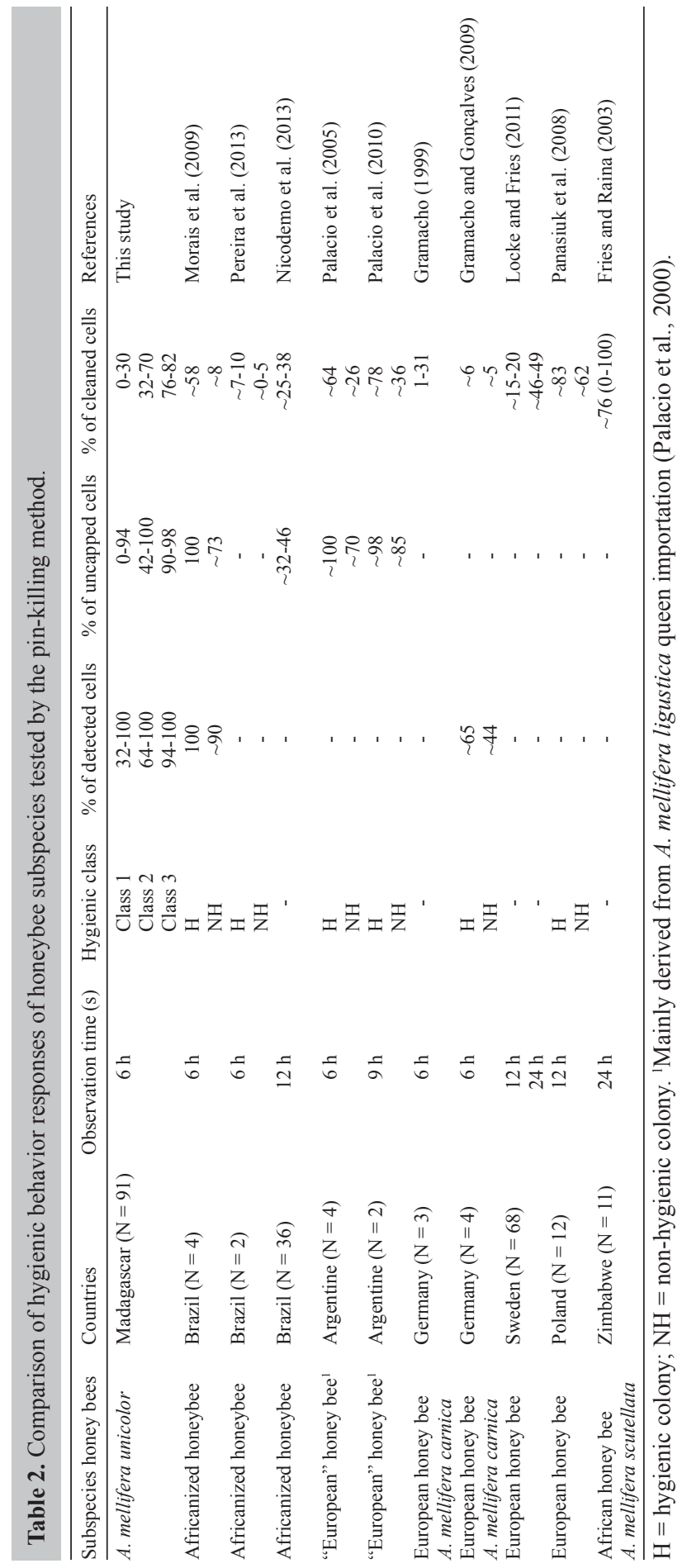




\section{DISCUSSION}

Based on the percentage of cleaned cells within $6 \mathrm{~h}$ after perforation, A. mellifera unicolor colonies were split in three classes according to different distribution modes. Compared to other subspecies tested after $6 \mathrm{~h}$ of pin-killing of the brood, Malagasy colonies from classes 2 and 3 were better at detecting, uncapping, and removing damaged brood than those of European (Gramacho, 1999; Gramacho and Gonçalves, 2009; Locke and Fries, 2011) and some of the Africanized honey bee populations (Nicodemo et al., 2013; Pereira et al., 2013). In hygienic European honey bee colonies, the rate of cleaned cells ranged from about 5 to $31 \%$ in A. mellifera carnica (Gramacho, 1999; Gramacho and Gonçalves, 2009) and reached 64\% in Argentinean honeybee stock, mainly derived from Apis mellifera ligustica queens according to Palacio et al. (2005). In hygienic colonies of Africanized honey bees, the rate of cleaned cells estimated with similar protocols ranged from 7 to 58\% (Morais et al., 2009; Pereira et al., 2013).

Comparison of our results with a broader range of studies (Table 2) for intermediate stages of HB reveals that the efficiency of Malagasy colonies at detecting and uncapping cells containing pin-perforated brood was comparable to the results reported from hygienic Africanized honey bees (Morais et al., 2009), and it was much higher than in European colonies (Gramacho and Gonçalves, 2009; Locke and Fries, 2011). As suggested, the greater hygienic behavior efficiency probably lies in the quick detection of brood death (Masterman et al., 2001; Gramacho and Spivak, 2003; Palacio et al., 2010). Our results suggest that workers of A. mellifera unicolor have a good ability to discriminate various cues emanated from the dead brood and/or have low thresholds to the stimulus, but they are also efficient at uncapping and removing dead brood from cells. Such an effective hygienic behavior had also been reported in African subspecies A. mellifera scutellata; the removal rate reported $24 \mathrm{~h}$ after perforation was considerably higher than the rate reported for Africanized bees (Fries and Raina, 2003).

Significant hygienic variability was found between colonies from the three studied regions (percentage of cleaned cells ranged from 0 to $65 \%$ in R1, 0 to $68 \%$ in R2, and 18 to $82 \%$ in R3). Pin-tests in our study were done at two different periods, winter (between April-October, R2) and summer (between November-March, R1 and R3), and a broad panel of climatic conditions and topography were observed in the three regions (Figure 1). Season, relative humidity, and temperature have been shown to influence hygienic success of colonies (Couto and Couto, 2006; Uzunov et al., 2014). HB of the same subspecies (A. cerana indica) was found to differ in various eco habitats (Athreya and Reddy, 2013). Therefore, part of the variation in the hygienic responses observed between regions could be due to the season, environment, and climatic factors.

Moreover, the PCA graph and the overall means of $F_{\mathrm{ST}}$ showed significant neutral nuclear genetic differentiation between regions, indicating that gene flow is restricted between the three studied regions. Since HB is a heritable trait, differences between colonies of the same apiary and differences in the distribution of hygienic responses among regions could also be partly explained by origin and genetic diversity of colonies.

In the region infested by $V$. destructor (R3), all colonies cleaned at least $18 \%$ of perforated cells within $6 \mathrm{~h}$; thus, very low levels of hygienic response were not found. Colonies harboring cleaned cells at the rate of 0 to $16 \%$ at $6 \mathrm{~h}$ are usually classified as non-hygienic (Palacio et al., 2005; Morais et al., 2009; Pereira et al., 2013) and are therefore highly susceptible to varroatosis. Apiaries from this infested region suffered serious colony losses (about $60 \%$ ) one year before our pin tests (Rasolofoarivao et al., 2013). Thus, the absence of such non- 
hygienic colonies in R3 and the shift observed in the distribution of $\mathrm{HB}$ could be explained by directional natural selection favoring the most hygienic colonies.

Highly hygienic colonies could be utilized in a breeding program to select for HB and provide Malagasy beekeepers with the means to reduce the incidence of $V$. destructor. Hygienic colonies could also have great economic interests, because they have been reported to produce more honey and pollen (Spivak and Reuter, 2001, Nicodemo et al., 2013) than non-hygienic colonies. Nevertheless, the actual degree of $V$. destructor tolerance of Malagasy colonies tested with the pin-killing method needs to be further evaluated in controlled tests by challenging the colonies with $V$. destructor mites. Other adaptive traits at the colony level such as grooming behavior and reduced mite reproduction ability may also affect the overall colony tolerance (Aumeier et al., 2000; Locke and Fries, 2011).

\section{ACKNOWLEDGMENTS}

We are grateful to the Malagasy beekeepers who participated in this study. We thank the following people: Andrianaivoariseta Niaina, FENAM and FITAME associations for their help with data collection, Chiroleu Frédéric and Le Squin Sandrine for statistical help, K.M. Gramacho for information about her PhD work. This work is part of the $\mathrm{PhD}$ by Rasolofoarivao Henriette, who is also the recipient of a grant from CIRAD-AIRD-Sud. Field work had been partly supported by CIRAD, the Enlargement and sustainability of the Plant Protection Network (ePRPV) project, the European Union, the French government, and Région Réunion.

\section{REFERENCES}

Athreya SVR and Reddy MS (2013). Variation of hygienic behaviour (nest cleaning behaviour) in honey bee, Apis cerana indica $\mathrm{F}$. in different eco habitats of South India. Curr. Biot. 7: 101-104.

Aumeier P, Rosenkranz P and Gonçalves LS (2000). A comparison of the hygienic response of Africanized and European (Apis mellifera carnica) honey bees to Varroa-infested brood in tropical Brazil. Genet. Mol. Biol. 23: 787-791.

Belkhir K, Borsa P, Chikhi L, Raufaste N, et al. (1996-2004). GENETIX 4.05, logiciel sous Windows TM pour la génétique des populations. Laboratoire Génome, Populations, Interactions, CNRS UMR 5000, Université de Montpellier II, Montpellier.

Boecking O and Spivak M (1999). Behavioral defenses of honey bees against Varroa jacobsoni Oud. Apidologie 30: 141-158.

Couto RHN and Couto LA (2006). Apicultura: manejo e produtos. FUNEP, Jaboticabal.

Franck P, Garnery L, Loiseau A, Oldroyd BP, et al. (2001). Genetic diversity of the honey bee in Africa: microsatellite and mitochondrial data. Heredity 86: 420-430.

Fries I and Raina S (2003). American foulbrood and African honey bees (Hymenoptera: Apidae). J. Econ. Entomol. 96: 1641-1646.

Fries I, Camazine S and Sneyd J (1994). Population dynamics of Varroa jacobsoni: a model and a review. Bee World 75: 5-28.

Ganzhorn JU, Lowry PP II, Schatz GE and Sommer S (2001). The biodiversity of Madagascar: one of the world's hottest hotspots on its way out. Oryx 35: 346-348.

Garnery L, Cornuet JM and Solignac M (1992). Evolutionary history of the honey bee Apis mellifera inferred from mitochondrial DNA analysis. Mol. Ecol. 1: 145-154.

Gramacho KP (1999). Fatores que interferem no comportamento higiênico das abelhas Apis mellifera. Doctoral thesis, Faculdade de Filosofia, Ciências e Letras de Ribeirão Preto, USP, Ribeirão Preto.

Gramacho KP and Spivak M (2003). Differences in olfactory sensitivity and behavioral responses among honey bees bred for hygienic behavior. Behav. Ecol. Sociobiol. 54: 472-479.

Gramacho KP and Gonçalves L (2009). Sequential hygienic behavior in Carniolan honey bees (Apis mellifera carnica). Genet. Mol. Res. 8: 655-663. 
Gramacho KP, Gonçalves LS, Rosenkranz P and De Jong D (1999). Influence of body fluid from pin-killed honey bee pupae on hygienic behavior. Apidologie 30: 367-374.

Gregorc A and Lokar V (2011). Selection criteria in an apiary of Carniolan honey bee (Apis mellifera carnica) colonies for queen rearing. J. Central Eur. Agric. 11: 401-408.

Guerra Jr JCV, Gonçalves LS and De Jong D (2000). Africanized honey bees (Apis mellifera L.) are more efficient at removing worker brood artificially infested with the parasitic mite Varroa jacobsoni Oudemans than are Italian bees or Italian/Africanized hybrids. Genet. Mol. Biol. 23: 89-92.

Johnson RM, Ellis MD, Mullin CA and Frazier M (2010). Pesticides and honey bee toxicity-USA. Apidologie 41: 312-331. Jombart T (2008). Adegenet: a R package for the multivariate analysis of genetic markers. Bioinformatics 24: 1403-1405.

Latreille P (1804). Notice des espèces d'abeilles vivant en grande sociétée, ou d'abeilles proprement dites, et description d'espèces nouvelles. Ann. Mus. Natl. Hist. Nat. 5: 161-178.

Locke B and Fries I (2011). Characteristics of honey bee colonies (Apis mellifera) in Sweden surviving Varroa destructor infestation. Apidologie 42: 533-542.

Lodesani M, Costa C and Man MC (2009). Limits of chemotherapy in beekeeping: development of resistance and the problem of residues. Bulletin of University of Agricultural Sciences and Veterinary Medicine Cluj-Napoca Animal Science and Biotechnologies 62 .

Masterman R, Ross R, Mesce K and Spivak M (2001). Olfactory and behavioral response thresholds to odors of diseased blood differ between hygienic and non-hygienic honey bees (Apis mellifera L.). J. Comp. Physiol. A 187: 441-452.

Mittermeier RA, Turner WR, Larsen FW, Brooks TM, et al. (2011). Global biodiversity conservation: the critical role of hotspots. In: Biodiversity hotspots (Zachos FE and Habel JC, eds.). Springer-Verlag, Berlin, 3-22.

Morais M, Francoy T, Pereira R, De Jong D, et al. (2009). Africanized honey bees are efficient at detecting, uncapping and removing dead brood. Genet. Mol. Res. 8: 718-724.

Nagode M and Fajdiga M (2011). The rebmix algorithm and the univariate finite mixture estimation. Commun. Stat. Theory Methods 40: 876-892.

Nicodemo D, De Jong D, Couto RH and Malheiros EB (2013). Honey bee lines selected for high propolis production also have superior hygienic behavior and increased honey and pollen stores. Genet. Mol. Res. 12: 6931-6938.

Palacio MA, Figini EE, Ruffinengo SR, Rodriguez EM, et al. (2000). Changes in population of Apis mellifera L. selected for hygienic behavior and its relation to disease tolerance. Apidologie 31: 471-478.

Palacio MA, Flores JM, Figini E, Ruffinengo S, et al. (2005). Evaluation of the time of uncapping and removing dead brood from cells by hygienic and non-hygienic honey bees. Genet. Mol. Res. 4: 105-114.

Palacio MA, Rodriguez E, Gonçalves LS, Bedascarrasbure E, et al. (2010). Hygienic behaviors of honey bees in response to brood experimentally pin-killed or infected with Ascosphaera apis. Apidologie 41: 602-612.

Panasiuk B, Skowronek W and Bieńkowska M (2008). Influence of genotype and method of brood killing on brood removal rate in honey bee. J. Apic. Sci. 52: 55-65.

Pereira RA, Morais MM, Francoy TM and Gonçalves LS (2013). Hygienic behavior of Africanized honey bees Apis mellifera directed towards brood in old and new combs during diurnal and nocturnal periods. Insects 4: 521-532.

Rasolofoarivao H, Clémencet J, Ravaomanarivo LHR, Razafindrazaka D, et al. (2013). Spread and strain determination of Varroa destructor (Acari: Varroidae) in Madagascar since its first report in 2010. Exp. Appl. Acarol. 60: 521-530.

Rasolofoarivao H, Clémencet J, Ravaomanarivo LHR, Razafindrazaka D, et al. (2015). Genetic diversity of the endemic bee: Apis mellifera unicolor (Hymenoptera: Apidae) in Madagascar. Apidologie DOI 10.1007/s13592-015-0362-1.

Rothenbuhler WC (1964). Behaviour genetics of nest cleaning in honey bees. I. Responses of four inbred lines to diseasekilled brood. Anim. Behav. 12: 578-583.

Solignac M, Vautrin D, Loiseau A, Mougel F, et al. (2003). Five hundred and fifty microsatellite markers for the study of the honeybee (Apis mellifera L.) genome. Mol. Ecol. Notes 3: 307-311.

Spivak M (1996). Honey bee hygienic behavior and defense against Varroa jacobsoni. Apidologie 27: 245-260.

Spivak M and Gilliam M (1998). Hygienic behavior of honey bees and its application for control of brood diseases and varroa. Part II. Studies on hygienic behaviour since the Rothenbuhler era. Bee World 79: 169-186.

Spivak M and Reuter GS (2001). Resistance to American foulbrood disease by honey bee colonies Apis mellifera bred for hygienic behavior. Apidologie 32: 555-565.

Techer M, Clémencet J, Turpin P, Volbert N, et al. (2014). Genetic characterization of the honey bee (Apis mellifera) population of Rodrigues Island, based on microsatellite and mitochondrial DNA. Apidologie Doi: 10.1007/s13592014-0335-9.

Uzunov A, Costa C, Panasiuk B, Meixner M, et al. (2014). Swarming, defensive and hygienic behaviour in honey bee colonies of different genetic origin in a pan-European experiment. J. Apic. Res. 53: 248-260.

Weir BS and Cockerham CC (1984). Estimating F-statistics for the analysis of population structure. Evolution 38: 13581370. 